\title{
Percepção de Adolescentes Aprendizes Sobre a Experiência do Primeiro \\ Emprego
}

Perceptions Of Adolescent Apprentices About The Experience Of First Job

Percepción De Adolescentes Aprendices Sobre La Experiencia Del Primero Empleo

Heloiza de Sousa, Denise Frozzi

\& Marucia Patta Bardagi

Universidade Federal de Santa Catarina

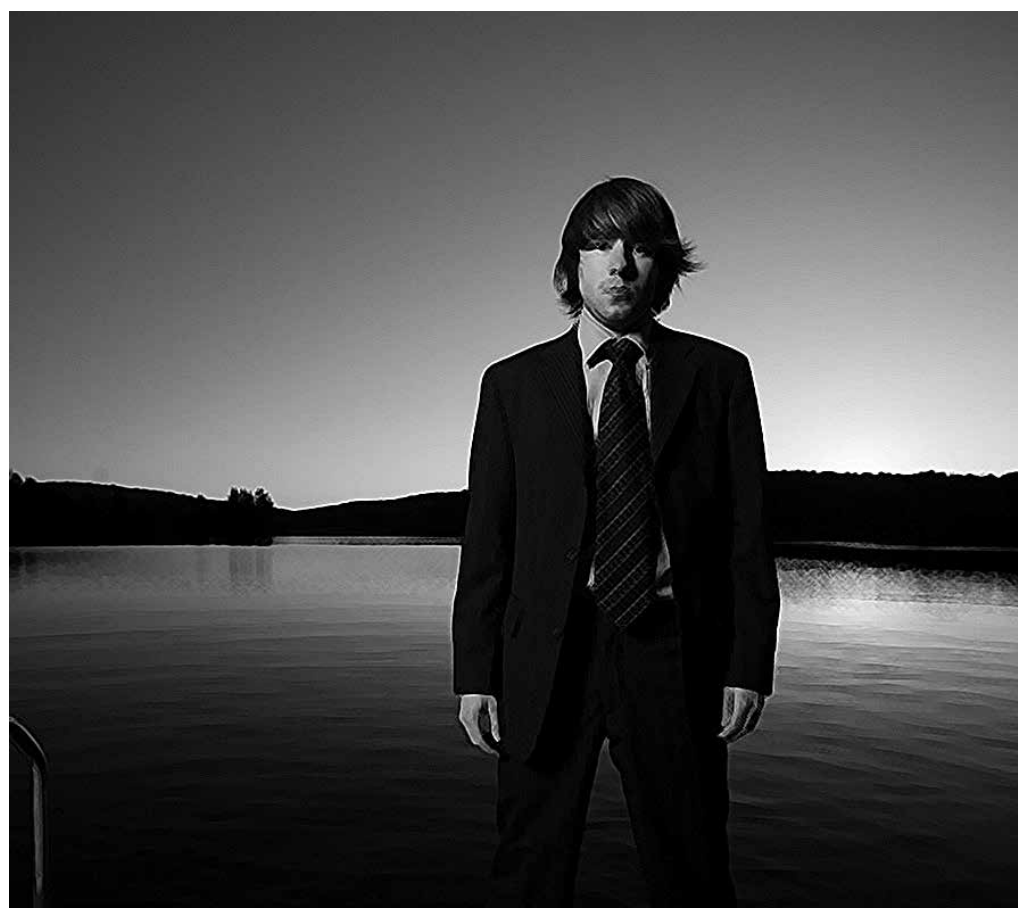


Resumo: Este estudo investigou como jovens aprendizes avaliam a inserção profissional através do primeiro emprego e que mudanças identificam em suas vidas a partir dessa experiência. Foi realizada uma entrevista focal com quatro adolescentes aprendizes catarinenses (dois meninos e duas meninas), entre 14 e 16 anos. Como pontos positivos, foram apontados o aumento da maturidade e da organização pessoal, o maior reconhecimento social (no trabalho e na família), a aquisição de conhecimentos, a mudança pessoal e o impacto do trabalho na escolha profissional. Os principais aspectos negativos foram a falta de tempo, a negligência com a própria saúde e a dificuldade com a troca constante de turmas e de educadores. Identificar as percepções desses participantes permitiu melhor compreensão do seu desenvolvimento pessoal e profissional, além de fornecer feedback às instituições promotoras da aproximação jovem-emprego e às empresas que os recebem. Novos estudos, de maior abrangência, poderão ampliar os aspectos aqui considerados.

Palavras-chave: Adolescentes. Mercado de trabalho. Trabalho. Escolha profissional.

Abstract: This study investigated how young apprentices evaluate professional insertion through their first job and what changes they identify in their lives from this experience. A focus group interview with four young apprentices from Santa Catarina (two boys and two girls), who were between 14 and 16 years old, was held. As main positive aspects there were the increase in maturity and personal organization, more social recognition (in work and family), skills acquisition, personal change and the impact of work on career choice. Main negative aspects were lack of time, neglect of their own health and the difficulty with the constant changing of classes and teachers. Identify the perceptions of these participants contributed to a better understanding of their personal and professional development, and provided feedback for the institutions that promote youth-employment approach and to companies that receive them. Further studies of larger scope can expand the aspects considered here.

Keywords: Adolescent. Labor market. Work. Vocational choice.

Resumen: Este estudio investigó como jóvenes aprendices evalúan la inserción profesional a través del primer empleo y que cambios identifican en sus vidas a partir de esa experiencia. Fue realizada una entrevista focal con cuatro adolescentes aprendices catarinenses (dos niños y dos niñas), de entre 14 y 16 años. Como puntos positivos, fueron apuntados el aumento de la madurez y de la organización personal, el mayor reconocimiento social (en el trabajo y en la familia), la adquisición de conocimientos, el cambio personal y el impacto del trabajo en la elección profesional. Los principales aspectos negativos fueron la falta de tiempo, la negligencia con la propia salud y la dificultad con el cambio constante de grupo de clase y de educadores. Identificar las percepciones de esos participantes permitió una mejor comprensión de su desarrollo personal y profesional, además de suministrar feedback a las instituciones promotoras de la aproximación joven-empleo y a las empresas que los reciben. Nuevos estudios, de mayor alcance, podrán ampliar los aspectos aquí considerados.

Palabras clave: Adolescente. Mercado de trabajo. Trabajo. Elección profesional.

Atualmente, observa-se que a questão financeira não é somente o que faz com que o trabalho seja claramente supervalorizado, mas também o valor moral e social que este representa dentro da cultura da qual fazemos parte. Todavia, essa percepção acerca do trabalho foi construída historicamente, e teve o seu conceito desenvolvido com o passar do tempo. Embora o termo trabalho seja utilizado de maneira reducionista para descrever as atividades remuneradas e executadas dentro das organizações, podese observar que ele mobiliza tanto energias físicas como mentais, além de emoções e sentimentos (Rizzo \& Chamon, 2011). trabalho é central na vida dos indivíduos dentro de uma sociedade, indo além dos limites do ambiente produtivo, e envolve, por exemplo, as relações familiares, os momentos de lazer e de descanso, os limites do dia e da noite e até mesmo a duração da vida. $\mathrm{O}$ trabalho se fundamenta não só como um aspecto de impacto econômico mas também social e psicológico para os trabalhadores.

No Brasil, a realidade do trabalho não se apresenta apenas para os indivíduos adultos, sendo substancial o contingente de jovens inseridos, formal ou informalmente, em atividades laborais, muitas vezes desde a infância (Instituto Brasileiro de Geografia e 
Segundo Mattos e Chaves (2010), Ramos e Menandro (2010) e Rizzo e Chamon (2011), a inserção na vida produtiva é um dos processos que marcam a transição para a vida adulta e o enfrentamento das responsabilidades adultas

(autorregulação, organização pessoal e financeira, lidar com cobranças e riscos, etc...).
Estatísca - IBGE, 2012). Segundo Mattos e Chaves (2010), Ramos e Menandro (2010) e Rizzo e Chamon (2011), a inserção na vida produtiva é um dos processos que marcam a transição para a vida adulta e o enfrentamento das responsabilidades adultas (autorregulação, organização pessoal e financeira, lidar com cobranças e riscos, etc...). Essa fase de transição, de mudanças, de adaptação e de ajustamento é, de acordo com Almeida e Pinho (2008), um momento de confronto entre o fim da infância e as reais exigências, seja de uma profissão ou tarefa específica, seja do mundo adulto como um todo.

A literatura tem apresentado uma polarização entre os aspectos positivos e os negativos gerados pela entrada precoce no mercado de trabalho. Quanto à descrição dos aspectos positivos, Ramos e Menandro (2010) e Rocha e Góis (2010) investigaram a mudança de identidade em adolescentes que vivenciavam a primeira inserção laboral, e verificaram, em seus discursos, que o trabalho foi visto de maneira positiva, na medida em que a aprendizagem possibilitada pela inserção profissional e a criação de uma rede de relações com o mundo do trabalho contribuiu para que houvesse uma reformulação de suas relações sociais. Os autores indicam que, após a inserção profissional, os adolescentes passaram a reconhecer-se como parte de um grupo social com perspectivas diferentes daquele no qual se enquadravam antes da entrada no mundo do trabalho.

No que diz respeito aos aspectos negativos, outros estudos indicam, ao compararem as representações sociais do trabalho entre adolescentes trabalhadores e não trabalhadores, que, entre os adolescentes trabalhadores, a relação trabalho/estudo mostrou-se prejudicial ao desenvolvimento escolar em muitos aspectos, como a falta de tempo para a realização de atividades extraclasse (leituras, exercícios e atividades grupais), e que as vantagens trazidas pelo trabalho parecem não conseguir superar as desvantagens e o custo da associação estudotrabalho (Oliveira, Sá, Fischer, Martins, \& Teixeira, 2001; Oliveira, Fischer, Teixeira, \& Amaral, 2003; Oliveira, Fischer, Martins, \& Sá, 2003; Oliveira, Fischer, Amaral, Teixeira, \& Sá, 2005; Oliveira, Fischer, Teixeira, Sá, \& Gomes, 2010). Ainda, a pesquisa realizada por Oliveira, Gomes, Benite e Valois (2006) com 200 adolescentes entre 14 e 22 anos, estudantes do ensino médio do Rio de Janeiro, verificou que a inflexibilidade dos horários do cotidiano dos adolescentes trabalhadores dificultava e até mesmo os impedia de participar de outras atividades tão importantes para o desenvolvimento da sua identidade, como, por exemplo, atividades esportivas/ recreativas, cursos de aperfeiçoamento e o convívio com a família. Além disso, o número de horas dedicadas ao sono apresentou-se reduzido entre os adolescente trabalhadores.

Essa preocupação com o bem-estar global das crianças e adolescentes e a constatação de que em muitas situações o trabalho de jovens é objeto de exploração, por ser realizado em condições precárias e efetivamente prejudiciais à saúde e ao seu desenvolvimento físico e psicológico, fez com que, entre outras razões, em 1990, fosse criado o Estatuto da Criança e do Adolescente (ECA), que estabelece importantes diretrizes para a proteção da atividade laboral na adolescência. Assim também, mais recentemente, a Lei da Aprendizagem (Lei no 10.097/2000), regulamentada pelo Decreto no 5.598/2005, assegura que, na condição de aprendiz (a partir de 14 anos), os adolescentes tenham formação técnico-profissional e realizem atividades que estejam também de acordo com as atividades escolares (Brasil, 2005). O contrato de aprendizagem pressupõe frequência escolar, horário especial para o exercício das atividades, programa de formação técnico-profissional e capacitação 
adequada ao mercado de trabalho. Assim, o decreto impõe limites ao trabalho dos adolescentes, visando a propiciar reais condições de aprendizagem e a minimizar os impactos negativos do trabalho precoce.

O trabalho de Lima e Minayo-Gomez (2003) avaliou aspectos próprios da inserção laboral de jovens aprendizes moradores de periferias da cidade do Rio de Janeiro. Os autores sugerem que o programa de aprendizagem fez com que os jovens tivessem maiores possibilidades de capacitação e de profissionalização. Além disso, as análises revelaram que o vínculo entre arte e cultura propiciado pelo projeto em questão criou novos modos de trabalho, em que valores como responsabilidade e liderança foram ativados, possibilitando, dessa forma, que o aprendiz se tornasse capaz de mudar não somente aspectos de sua própria vida mas também do grupo em que estava inserido. Nos estudos de Mattos e Chaves (2006, 2010), também realizados com adolescentes aprendizes participantes de um programa de aprendizagem desenvolvido por uma ONG em Salvador, observou-se que os elementos centrais das representações que esses jovens têm sobre o trabalho se relacionam com a possibilidade de obterem remuneração que contribuísse tanto para o próprio sustento quanto para o da família. O trabalho também é visto por esses jovens não somente como aquele que aumenta as responsabilidades do dia a dia, mas também como possibilidade de aprendizado e de desenvolvimento de novas habilidades. Os autores ressaltam que os pontos positivos ou negativos desse aumento de responsabilidade dependem das interpretações das experiências de cada um, pois, para alguns aprendizes, esse aumento de responsabilidade contribui para que se tornem mais organizados, mais ativos e planejem melhor suas atividades, além de estudarem e aprenderem mais.
No entanto, para outros adolescentes, essa responsabilidade os torna mais cansados e dificulta o bom desempenho nos estudos. Para superar essas dificuldades e manter um equilíbrio entre essas atividades, os adolescentes ressaltam a importância de ter o apoio não somente dos amigos mas também de professores e supervisores.

Embora se perceba que o trabalho na infância e adolescência é alvo de vários estudos que buscam compreender como a execução de atividades laborais produz implicações para o desenvolvimento físico, psíquico e social dessa população, de acordo com Amazarray, Thomé, Souza, Poletto e Koller (2009) e Mattos e Chaves, ainda são poucos os estudos que têm como objetivo a investigação de como jovens trabalhadores vivenciam a primeira inserção laboral. Mais escassos ainda são os estudos que buscam, através da percepção dos próprios adolescentes aprendizes, compreender que tipo de implicações o programa de aprendizagem, regulamentado desde 2005, traz para o dia a dia desses jovens. Tendo em vista a importância que o trabalho exerce na vida das pessoas e do quanto influencia o desenvolvimento da identidade de jovens adolescentes, este estudo objetivou conhecer como jovens participantes de um programa de aprendizagem de Santa Catarina avaliam a inserção na vida profissional através do primeiro emprego e quais mudanças e transformações identificam em suas rotinas de vida, expectativas de futuro e escolha profissional a partir dessa experiência. O trabalho pretendeu avaliar, ainda, os aspectos mais positivos e também os mais difíceis das experiências de trabalho e aprendizagem. Pretende-se que os resultados deste estudo possam servir de feedback para as instituições que promovem a inserção de adolescentes no mercado de trabalho e organizam os cursos de formação técnico-profissional, com o objetivo de potencializar as aprendizagens e o desenvolvimento desses jovens. 


\section{Método}

\section{Participantes}

Participaram deste estudo quatro jovens aprendizes (dois meninos e duas meninas), com idades entre 14 e 16 anos, da região da grande Florianópolis (SC). Os participantes trabalhavam há pelo menos 18 meses em atividades relacionadas às áreas administrativas e/ou de atendimento e, como prevê o modelo de aprendizagem, frequentavam regularmente as aulas de capacitação teórica. Os adolescentes são frequentadores de escolas públicas da região e pertencem a famílias de baixa renda.

\section{Instrumentos}

Para a obtenção dos dados, foi realizada uma entrevista de grupo foco (Krueger, 1988; Morgan, 1988), método de escolha quando se pretende compreender a formação de percepções, sentimentos e atitudes na interação com outras pessoas. De acordo com Johnson (1994), parte-se do pressuposto de que a energia gerada pelo grupo resulta em maior diversidade e profundidade de respostas, em que o esforço combinado do grupo produz mais informações e possui maior riqueza de detalhes do que o somatório das respostas individuais coletadas em entrevistas ou questionários. Os tópicos propostos aos adolescentes versaram sobre as expectativas e a motivação que os levaram a ingressar no programa de aprendizagem, a experiência de ser aprendiz, a relação trabalho e estudo e as principais mudanças percebidas no cotidiano (familiar e com os amigos, por exemplo) a partir dessa primeira experiência laboral, entre outros.

\section{Procedimento}

O presente estudo caracteriza-se como um estudo qualitativo de natureza exploratório-descritiva. Os alunos de duas turmas vespertinas de aprendizagem foram convidados a permanecer em sala após o término da aula a fim de conhecerem os objetivos e a estrutura da pesquisa. Cerca de 15 alunos foram convidados a participar do estudo, comparecendo com a autorização dos responsáveis a um encontro marcado em um sábado, no mesmo local das aulas teóricas. No dia da entrevista, quatro alunos compareceram, compondo a amostra do estudo. Para a coleta de dados, foi utilizada a entrevista de grupo foco, em que se buscou conhecer a percepção dos adolescentes acerca da experiência de aprendizagem e do trabalho nas empresas. A sessão foi gravada com o consentimento dos participantes, e teve duração aproximada de uma hora. No início, a mediadora forneceu informações acerca dos objetivos do grupo focal, do andamento da atividade, do uso do gravador, etc. A sessão foi transcrita na íntegra e submetida à análise de conteúdo (Bardin, 1977), buscando-se construir categorias temáticas e identificar semelhanças e diferenças dos participantes em relação às mesmas. Para manter o sigilo das informações, foram utilizados nomes fictícios que foram escolhidos pelos próprios adolescentes. Os adolescentes assinaram um Termo de Consentimento Livre e Esclarecido e foram autorizados por seus responsáveis a participar do estudo. A pesquisa foi submetida e aprovada pelo Comitê de Ética da Universidade Federal de Santa Catarina.

\section{Resultados e discussão}

Com base na análise de conteúdo da sessão com o grupo focal e nas questões que nortearam este estudo, foram criadas nove categorias temáticas: organização e planejamento pessoal, saúde, mudanças comportamentais, família e amigos, escola, colegas e supervisores, significado do trabalho, escolha profissional e avaliação do programa de aprendizagem. 


\section{Organização e planejamento pessoal}

Essa categoria apresenta aspectos relacionados a conseguir estabelecer prioridades, identificar os próprios limites e dividir as tarefas, e, embora esses aspectos possam ser considerados positivos, percebe-se que, inicialmente, os jovens aprendizes não tiveram suporte e encontraram dificuldades para estabelecer um equilíbrio entre as atividades, como ilustram os exemplos a seguir:

- Eu já criei uma rotina. Eu sei quando eu tô cansada que eu preciso dormir, que eu não aguento mais... eu sei os meus limites. Eu pus limite em mim, porque, no começo, quando eu comecei a trabalhar, eu ficava uma ou duas horas a mais trabalhando, achava: 'Ah não, se eu não terminar isso aqui hoje, daí eu só venho terça-feira pra cá', e eu me preocupava muito e acabava ficando até tarde, e chegava às vezes $9 \mathrm{~h}$ da noite em casa, sendo que era pra mim chegar às 7h. Então, com o tempo, eu fui me adaptando, criando uma rotina, e sabendo dividir o meu tempo. (Caroline, 15 anos)

- Eu consegui dividir bem minhas horas de estudos, trabalho. Eu sei a hora que eu tenho que parar e ir pra casa. No início, eu fazia isso também igual à Caroline, de ficar até mais tarde. Eu vi que não era isso, que eu podia parar, voltar no outro dia e fazer. Foi bom assim, porque agora eu consigo separar o que eu tenho que fazer agora e o depois, porque não adianta que eu não vou conseguir fazer tudo em uma hora só. (Charles, 16 anos)

Observa-se também que, inicialmente, houve uma falta de clareza por parte dos aprendizes sobre o limite de horas que deveriam ser cumpridas, embora as leis do Programa de Aprendizagem estabeleçam claramente que a duração do trabalho do aprendiz não deve exceder seis horas diárias, podendo ser de até oito horas diárias para os aprendizes que já tenham concluído o ensino fundamental, se nelas forem computadas as horas destinadas à aprendizagem teórica. De acordo com Amazarray et al. (2009), muitas consequências negativas podem ser acarretadas por essa falta de controle sobre o trabalho, e, no caso dos adolescentes, isso implicaria aspectos como, por exemplo, construção da identidade de trabalhador, submissão a condições laborais desfavoráveis e passividade frente às relações de trabalho. Dessa forma, no momento da contratação dos aprendizes, é necessário que recebam maiores informações sobre como se dá o funcionamento do programa, pois maior clareza sobre os limites de horas e atividades que o aprendiz deverá cumprir durante o período poderá facilitar a sua adaptação nesse novo momento da vida. Além disso, o estabelecimento de rotinas do trabalho parece auxiliá-los também na maneira como lidam com outros aspectos do cotidiano, como o estudo, a saúde e o lazer.

\section{Saúde}

Embora os adolescentes tenham relatado maior aprendizado na administração do tempo para a realização das tarefas, observase, nos relatos a seguir, que esse foi o principal motivo para que sua saúde fosse prejudicada, gerando, por exemplo, problemas de sono, problemas intestinais, alimentação ruim e falta de energia. Os discursos destacam ainda uma supervalorização do trabalho em detrimento da própria saúde, embora pareça existir uma contradição, uma vez que o trabalho é descrito como a melhor opção para esse momento da vida, como pode ser observado nos depoimentos a seguir:

- A única coisa assim de dificuldade é,
eu não boto limites em mim. Eu tenho
mania de estudo, muito, e isso acaba me
prejudicando; sabes, às vezes eu vou dormir
duas horas da manhã, três da manhã e ter
que acordar às cinco e meia no outro dia,
pra sair seis e quarenta de casa. Aí eu tenho
que controlar isso, mas é o cansaço. Chega
uma hora que você: 'Ai meu Deus o que
que eu tô fazendo? Por que que eu estou
fazendo?' Mas o resto... (Alice, 14 anos)
- Eu acho que foi me adaptar ao horário,
sair direto da escola pra ir pro trabalho, pra 
Esses achados vão ao encontro dos trabalhos de Fischer et al. (2003) e de Oliveira et al., (2005, 2006), que verificaram entre adolescentes trabalhadores maior percepção de cansaço, sono durante o dia, indisposição e dores pelo corpo. ir pra curso, essas coisas. Me adaptar aos horários assim, de não mais comer em casa, de comer na rua. Já peguei várias doenças do estômago, infecção, essas coisas, por causa de não ter tempo nem espaço assim pra comer direito. (Caroline, 15 anos)

- Minha dificuldade foi mais com adaptação de horário. Eu chegava em casa no início mais cansado, só que agora eu sei como aguentar tudo isso. (Charles, 16 anos)

Esses achados vão ao encontro dos trabalhos de Fischer et al. (2003) e de Oliveira et al., $(2005,2006)$, que verificaram entre adolescentes trabalhadores maior percepção de cansaço, sono durante o dia, indisposição e dores pelo corpo. Esses autores sugerem que provavelmente influenciados pelos horários rígidos e palas responsabilidades do trabalho, esses adolescentes deixam de priorizar as demais atividades do dia a dia e os cuidados consigo mesmos.

\section{Mudanças comportamentais}

Todos os adolescentes relataram ter observado mudanças comportamentais, sendo a maioria relacionadas com um maior sentimento de responsabilidade, dentro e fora do trabalho, aquisição de novos conhecimentos, capacidade de comunicação e desenvoltura pessoal aumentadas, bem como maior tolerância, observadas nos exemplos a seguir:

-Eu fiquei mais responsável, eu era muito jogado às traças. Fiquei mais responsável e tô gostando. Aprendi bastante lá com elas. (...) Eu comecei a ter mais paciência também. Conversar com as pessoas, eu acho que eu converso melhor, então, antes eu ficava envergonhado de falar com as pessoas com o cargo maior que o meu, mas agora não, eu falo mais tranquilamente. (Charles, 16 anos)

- (...) Eu também aprendi a falar direito, exemplo, não ficar usando gírias o tempo todo. O jovem tem muita mania disso, né, ainda bem que eu fui perdendo. Me ensinaram a como mandar uma mensagem para uma pessoa formalmente. Olha, eu aprendi muita coisa. Eu acho assim, o meu grau de responsabilidade aumentou. (...) Eu era muito estressada, ainda sou um pouquinho, porque tem essa pressão toda, e tá, e eu não suportava barulho, e ele fez com que eu não invadisse a privacidade dos outros pedindo grosseiramente. (Alice, 14 anos)

- Eu sinto assim que eu fiquei mais responsável, fiquei mais atento... fiquei mais bem educado assim, comecei a conversar com todo mundo. (Willian, 16 anos)

- A minha responsabilidade aumentou muito mais... E eu aprendi muita coisa lá dentro, tanto como falar, como se comportar. Todas as coisas eu aprendi lá. ... Então, eu aprendi a me controlar mais, a controlar os meus sentimentos. (Caroline, 15 anos)

É interessante salientar que para nenhum dos entrevistados esse aumento da responsabilidade aparece de modo negativo, ao contrário, esse compromisso é visto pelos adolescentes como motivo para se sentirem orgulhosos, já que o trabalho os faz sentirem-se mais valorizados. Essa percepção de maior valorização, principalmente no modo como lidam com as pessoas e com os próprios sentimentos, parece também ter gerado um aumento da autoestima. Esses resultados se alinham aos obtidos por Mattos e Chaves (2006, 2010) e Amazarray et al. (2009), em que também são identificados, a partir das falas de adolescentes aprendizes, uma percepção de maior aprendizado, de autonomia em relação à infância e maior sentimento de responsabilidade.

\section{Família e amigos}

Nessa categoria, observou-se pelo discurso dos adolescentes que, após a inserção no mundo do trabalho, houve mudança significativa nas relações que estabelecem com seus familiares e amigos. No que se refere à família, houve mudança na relação com os pais, sendo esta agora mais igualitária, além de perceberem que recebem mais 
confiança e atenção, como no exemplo a seguir:

- Comigo, meu pais começaram a dar mais atenção pra mim. Quando eu comecei a trabalhar, começaram a me dar mais liberdade. Começaram a olhar mais pra mim mesmo. (Charles, 16 anos)

Observa-se também que as mudanças comportamentais percebidas após a inserção laboral foram importantes para que houvesse maior reflexão sobre os assuntos próprios da relação com os pais, bem como ajudaram a evitar ou a solucionar conflitos com os pais:

- (...) Eu acho que consegui levar mais a sério os conselhos que os meus pais me davam. Consegui conversar mais com o meu pai, porque ele é uma pessoa muito difícil, e eu aprendi como é o trabalho, às vezes as pessoas fala uma brincadeirinha, uma coisa assim. Você aprende que entra por um ouvido, e sai pelo outro, então eu aprendi a fazer isso com o meu pai, aprendi a ter paciência. (Caroline, 15 anos)

De acordo com Amazarray et al., "coesão familiar, comunicação, qualidade do relacionamento entre pais e filhos e práticas educativas envolvendo afeto, reciprocidade, estabilidade, confiança e equilíbrio de poder são fatores muito importantes para o processo de desenvolvimento da identidade dos adolescentes" (2009, p. 333). Nesse sentido, se o trabalho favorece essa aproximação entre pais e filhos e aumenta a confiança dos adolescentes em si mesmos, esse resultado é extremamente benéfico tanto a curto quanto a longo prazo. Em relação aos amigos, observaram-se no discurso dos jovens dois tipos de situações: por um lado, a falta de tempo ocasionada pelas exigências do cotidiano dificultou o relacionamento com os pares que não têm as mesmas experiências, enquanto, por outro lado, o fato de estar inserido no ambiente de trabalho gerou aproximação com novos grupos e também com os amigos que exerciam algum tipo de atividade remunerada, como se pode ver:
- (...) E aí nenhum amigo meu trabalhava, daí eles me chamavam pra sair com eles no outro dia, eu não ia, porque tava lá no trabalho. E isso foi ruim pra mim, mas com o tempo, fui me adaptando, vendo que tinha final de semana, à noite é dia de sair com eles também. Daí foi só isso assim, minha dificuldade mesmo. (Charles, 16 anos)

- E com meus amigos, tudo, a gente começa a interagir sobre o que a gente faz no trabalho, porque todos os meus amigos trabalham. E aí a gente começou... sempre ficava debatendo assim todos os dias. (Willian, 16 anos)

Talvez essas mudanças observadas em relação à família e aos amigos tenham se dado pelo fato de que, ao assumirem uma certa responsabilidade dentro do ambiente de trabalho, acabam assumindo também um novo papel dentro da sociedade, sendo vistos não mais como aqueles que são imaturos e isentos de responsabilidade, mas sim, como aqueles que têm deveres a ser cumpridos e conseguem fazê-los. Os trabalhos de Rocha e Góis (2010) e de Ramos e Menandro (2010) também sinalizam esses aspectos e argumentam que há, após a inserção laboral, um reconhecimento social e um sentimento de pertencimento a um grupo social distinto do qual faziam parte, o que significa, para esses jovens, de acordo com Rizzo e Chamon (2011), a entrada definitiva na vida adulta.

\section{Estudo}

A relação trabalho e estudo é vista pelos adolescentes de forma positiva, à medida que conseguiram, depois da inserção laboral, um aumento da motivação e do esforço nos estudos e, em consequência, melhor desempenho escolar.

- O meu desempenho na escola aumentou, eu era muito assim, como eu vou dizer... (Alice, 14 anos).

- E também, porque eu não gosto de ficar em casa estudando, porque em casa é muito barulho, então eu comecei a estudar mais 
e minhas notas melhoraram muito, por isso que o trabalho é um ambiente bom de estudar, e às vezes tem bastante tempo pra estudar. (Caroline, 15 anos).

- (...) No colégio, ajudou bastante, minhas notas melhoraram. (Charles, 16 anos).

Esses resultados são consistentes com os trabalhos de Mattos e Chaves (2006, 2010), em que alguns dos adolescentes entrevistados afirmaram que, a partir da inserção laboral, passaram a ter maior concentração e dedicação em relação às atividades escolares. Uma vez que a percepção positiva de mudança nos estudos depois do início do trabalho não é unanimidade na literatura com adolescentes trabalhadores, os autores ressaltam que essa maior disposição para exercer as duas atividades irá depender das percepções e das experiências de cada um bem como das condições específicas do trabalho realizado, que podem ser mais favorecedoras das atividades escolares ou ter uma relação mais próxima com os conteúdos ou os interesses dos alunos.

Pode-se dizer que a consciência da importância da continuidade dos estudos é uma característica desse grupo, uma vez que a conciliação entre trabalho e estudo é proporcionada e muito enfatizada pelo Programa de Aprendizagem, mas que, em muitas situações de trabalho, observa-se que os adolescentes precisam escolher entre uma atividade ou outra, sendo que muitas vezes os estudos são deixados de lado na priorização pelo trabalho (Pochman, 2005). O modelo de aprendizagem pode constituir-se em uma tentativa de reaproximação da relação escola-trabalho, historicamente associadas desde o início, mas que, ao longo do processo de transformação dos mundos produtivo e escolar, sofreram um abissal afastamento (Saviani, 2007).

Outro aspecto que cabe discutir aqui é a possibilidade de o trabalho executado como aprendiz relacionar-se aos interesses pessoais do adolescente e constituir-se em uma escolha profissional futura, aumentando ainda mais a relação com os estudos. Para aqueles adolescentes que vislumbram a possibilidade de continuarem a trabalhar em seus locais de aprendizagem ou adquirirem formações profissionais que thes foram apresentadas por pessoas com as quais convivem durante as atividades, cresce a importância da continuidade dos estudos e da formação escolar. O contato e os modelos de trajetórias escolares e profissionais ligados à continuidade dos estudos que são apresentados aos estudantes durante o exercício do Programa de Aprendizagem podem contribuir em muito para a ressignificação do papel da escola e da formação.

\section{Colegas e supervisores}

A importância que os supervisores exercem no desenvolvimento e na aprendizagem dos jovens é evidente a partir dos seus relatos. Observa-se que estes se sentem valorizados no ambiente de trabalho quando o supervisor é próximo, e a possiblidade de terem uma relação próxima com os supervisores indica a existência de maior abertura para conversar sobre diferentes assuntos, inclusive pessoais.

- E eu tenho uma hora de estudo com o meu orientador. O meu orientador participa bastante da minha atividade, ele até mesmo já veio aqui no CEE, já conversou com a turma, tal. ... Ele me deu todas as instruções do que eu deveria fazer, me ensinou a atender o telefone, me ensinou a fazer um monte de coisas, aí passou desse ano, como ele viu que eu era bem interessada, me chamou e começou a me dar aula. (Alice, 14 anos)

- Eu converso muito com a minha chefe, ela é muito gente boa assim, converso sobre vários assuntos do trabalho, de fora do trabalho. (Willian, 16 anos).

- (...) Eles pegaram outro menor aprendiz também, porque de manhã o trabalho era muito grande, não tava dando conta, mas 
eles gostam bastante de mim. O pessoal ajuda quando precisa, dá uma força quando precisa, não só no trabalho, mas pessoal, tudo. (Charles, 16 anos)

Esse desenvolvimento de vínculos com os supervisores e os colegas é claramente um ganho importante para os adolescentes, pois estes parecem sentir-se mais motivados não somente para realizar as tarefas específicas do trabalho. Além disso, a expansão dessa confiança estabelecida entre supervisor e aprendiz para fora dos muros da empresa parece servir de apoio para que consigam lidar melhor com as exigências do dia a dia. Com uma postura semelhante a essa, Bressan, Godoy e Lunardelli (2004) argumentam que os incentivos à comunicação aberta entre aprendizes e supervisores podem contribuir de maneira significativa para que os aprendizes consigam desenvolver e assumir uma postura mais autônoma e crítica diante de diferentes situações referentes ao trabalho. Nesse sentido, a escolha do profissional que vai assumir o papel de supervisor do jovem aprendiz é um dos pontos fundamentais do sucesso dessas iniciativas, assim como também a preparação do grupo de funcionários para a chegada e a integração do adolescente trabalhador.

\section{Significado do trabalho}

A partir do que foi dito abaixo, observou-se que existe uma desconstrução da imagem que o trabalho representava para os jovens antes da experiência de aprendizagem, passando de algo que somente demanda esforços e que é realizado em um espaço onde não existe amizade ou cooperação para algo mais prazeroso, em que também existe a possibilidade de expandir as relações afetivas:

- Eu achava que era uma coisa mais monótona, assim, que eu via todo mundo falar, que cada um fica no seu canto fazendo o seu trabalho, mas não. É bem descontraído, eu gosto bastante. (Charles, 16 anos)
- Bom, no meu trabalho, quando eu entrei, eu tinha bastante aquele pensamento: 'Ah, eu vou entrar vou fazer só o meu trabalho, não preciso falar com ninguém, eu só dou bom dia, e deu. (Alice, 14 anos)

- Eu imaginava que eu seria mais cobrada. Eu imaginava mais assim, um lugar onde todo mundo só queria saber de trabalhar, ninguém tava nem aí um com o outro, era igual a Alice falou, era só pronto chegar, dar bom dia, fazer o seu serviço, e acabou. (Caroline, 15 anos)

Como apontam os estudos de Gonçalves e Coimbra (2002) e de Lemos (2000), os adolescentes tendem cada vez mais a valorizar as dimensões extrínsecas do trabalho dinheiro, poder, prestígio social - além de salientar a dimensão emocional mais negativa da atividade profissional, relacionando-a ao cansaço e ao estresse. Para os adolescentes de baixa renda, possivelmente inseridos em contextos de trabalho precarizado exercido por pais e amigos, esses podem ser os principais aspectos associados ao trabalho. A experiência positiva como aprendiz pode propiciar uma ressignificação do significado do trabalho para esses jovens, aproximando-os de uma visão do trabalho como possibilidade de expressão pessoal da identidade, de compartilhamento de experiências e de contato social positivo. Ao mesmo tempo, uma experiência negativa de aprendizagem pode reforçar estereótipos negativos e cristalizar percepções do trabalho como sofrimento e sacrifício, sem retorno positivo exceto a sobrevivência, e favorecer também o distanciamento entre trabalho e estudo.

\section{Escolha profissional}

Nos discursos dos jovens, observou-se que a experiência de aprendizagem os ajudou a identificar mais claramente preferências e a especificar as escolhas profissionais que gostariam de fazer. O contato com as profissões no ambiente de trabalho fez 
com que pudessem conhecer mais sobre determinadas áreas, e assim orientassem suas escolhas. Além disso, observou-se também a influência que os supervisores podem exercer nessa decisão tão importante, como exemplificado a seguir:

- Me ajudou muito, porque eu entrei, no primeiro dia que eu entrei, eu sabia a faculdade que eu ia fazer, ia fazer Gastronomia, eu acho que não deu sete meses, eu mudei totalmente. Esse ano eu primeiro: 'Ah não, vou fazer Gastronomia e Administração'. Eu amei o trabalho que eu tava fazendo. (Caroline, 15 anos)

- Eu entrei na empresa querendo fazer Educação Física, daí, como é uma empresa de Engenharia, eu comecei a me enturmar com o pessoal e mudei pra Engenharia também, só que Engenharia Mecânica, parece ser uma área boa, que eu gostei, assim. (Charles, 16 anos)

- (...) Eu queria fazer Medicina, na verdade, daí eu fiquei pensando: Medicina, Medicina, mas por que, né, por quê que eu fui tanto pra essse lado. Aí o que eu fiz, eu conheci a área da Medicina. Ele (supervisor) me mostrou também, porque ele fez três anos de Medicina, né, e depois ele me levou pra Odonto, daí foi aí que eu fui mudando minha ideia e tal, e foi aí que eu foquei nesse objetivo de eu vou fazer Odontologia, daí eu não mudei mais de profissão. (Alice, 14 anos)

O processo de escolha profissional, de acordo com Santos (2005), baseia-se na realidade do próprio adolescente, sendo este influenciado tanto pela família quanto por terceiros. Observa-se que, por meio do Programa de Aprendizagem, os adolescentes pesquisados puderam ter um contato mais próximo com algumas áreas de conhecimento, o que parece ter contribuído de forma significativa para que tivessem mais clareza sobre possibilidades de inserção, atividades profissionais, ambientes de trabalho e modelos profissionais fora do âmbito familiar, o que facilitou as escolhas que pretendiam fazer em relação ao futuro. Aqui o trabalho foi um campo muito importante para a exploração vocacional, aspecto chave para a realização de escolhas consistentes (Teixeira, Bardagi, \& Hutz, 2007).

\section{Avaliação do Programa de Aprendizagem}

Nessa categoria, os adolescentes indicaram que alguns temas discutidos em aula foram importantes na medida em que podiam ser vivenciados depois ou concomitantemente na execução das tarefas de aprendizagem. No entanto, a falta de uma sequência lógica entre os assuntos tratados no curso teórico, a rigidez que impedia mudanças de foco ou a flexibilização dos temas para melhor atender as necessidades de cada turma ou tipo de trabalho exercido pelos jovens foram bastante criticados. Observou-se também um descontentamento com a falta de vínculo em relação aos professores. Não somente a ruptura inesperada que costuma acontecer ao longo do tempo entre os professores com o programa gerou esse descontentamento, mas também a separação que frequentemente é feita com as turmas, como pode ser visto nos depoimentos a seguir:

- Olha, o que destacou assim no curso é que a gente já passou por vários educadores né; todos eles são ótimos, com todos eles eu consegui aprender alguma coisa (...). (Alice, 14 anos)

- E a gente, quando tá se adaptando com a pessoa, a gente tá com uma aula legal, tá com uma dinâmica, eles pegam e tiram os nossos professores, sabes, ou separam as turmas como fizeram, que deu aquela revolta toda. (Caroline, 15 anos)

- E também eu acho que, não sei. Parar um professor e analisar: 'Ah, o que que a gente deve ensinar pra essa turma de aprendizes, vamos levar as profissões, quais é, as empresas. Porque às vezes eles ensinam umas coisas que assim, sabes, não sei uma coisa que não tem nada a ver com ninguém assim da turma, ninguém, sabes, tá nem aí pra essa coisa, então não vai prestar atenção. (Caroline, 15 anos) 
Aqui é importante salientar novamente a participação fundamental do professor, que é figura de referência para o jovem aprendiz. Assim como a figura do supervisor apareceu nos relatoss como fonte de apoio, modelo profissional e incentivador do adolescente dentro das empresas, há um ressentimento pelo fato de os professores não permanecerem tempo suficiente com os alunos no curso teórico, o que leva ao desengajamento da turma. Esse descontentamento com a troca sistemática de educadores foi unânime entre os participantes, e constitui um aspecto importante a ser considerado pelas instituições formadoras como fundamental para a adesão e a permanência dos alunos. Além disso, a possibilidade de flexibilização dos conteúdos para que se adaptem melhor às atividades desenvolvidas pelos alunos durante o trabalho nas organizações também foi uma sugestão compartilhada por todos os participantes.

\section{Considerações Finais}

Este estudo voltou-se para a compreensão do processo de inserção laboral de um grupo de jovens participantes de um Programa de Aprendizagem em Santa Catarina. Para tanto, partiu-se do pressuposto de que, para se compreender melhor uma dada realidade, é necessário investigar com um olhar mais atento os diversos aspectos nela envolvidos; no caso dos adolescentes trabalhadores, buscou-se explorar aspectos como as expectativas que os levaram a ingressar no Programa de Aprendizagem, a experiência de ser aprendiz, a relação trabalho e estudo, as principais mudanças percebidas no cotidiano (familiar e com os amigos) e a avaliação que fazem de seu processo de aprendizagem.

A experiência no Programa de Aprendizagem é vista pelos adolescentes, de um modo geral, de forma positiva, mas é importante resaltar que essa visão se dá mais pela oportunidade que tiveram de inserção no mercado de trabalho, ou seja, pela parte prática do programa, enquanto a parte teórica (o curso de formação) não é tão bem avaliada e trouxe as maiores queixas dos participantes. Aqui pode-se pensar em um ponto de fragilidade desses programas, que, em muitos casos, pode levar à desmotivação e ao progressivo desengajamento de alguns jovens das atividades como um todo. Nesse ponto, esses resultados sugerem uma reavaliação da forma como os programas teóricos são montados, os conteúdos são escolhidos e os professores são selecionados, para que se potencializem nos cursos o bom desenvolvimento e as aprendizagens ocorridas no exercício laboral. Parece, ainda, ser muito importante para os jovens aprendizes a formação do vínculo com as turmas e os professores, o que deve ser facilitado; as constantes trocas de alunos e a rotatividade dos professores contribuem para menor satisfação com o tempo passado nos módulos teóricos, que muitas vezes são percebidos como um aspecto completamente desvinculado da atividade profissional. Como a própria Lei da Aprendizagem (Lei no 10.097/2000), regulamentada em 2005, assegura que os adolescentes tenham formação técnico-profissional, capacitação adequada ao mercado de trabalho e realizem atividades teóricas e práticas que estejam integradas, é fundamental que os programas estabeleçam avaliações constantes acerca desses objetivos e incluam as percepções dos jovens participantes nessas avaliações.

Em relação à experiência de trabalho em si, embora os aspectos de menor cuidado com a saúde e falta de tempo para engajar-se nas atividades de lazer e no contato com os amigos, muito enfatizados na literatura sobre o tema (Oliveira et al., 2001, 2005, 2006, 2010), tenham sido citados também aqui, a avaliação do primeiro emprego e da experiência de aprendiz foi majoritariamente positiva. Ressalta-se principalmente a satisfação dos participantes com a melhoria do desempenho e a motivação para os estudos, 
as relações mais próximas e igualitárias com os pais, a criação de novos vínculos sociais e a facilitação das escolhas profissionais que a experiência de trabalho proporcionou. Nesse sentido, é preciso ter cuidado ao avaliar o tipo e as condições do trabalho exercido por jovens no Brasil, uma vez que os resultados prejudiciais e que impõem restrições ao desenvolvimento podem não representar a maior parte das experiências em curso. Possivelmente aquele trabalho executado sem monitoramento, em condições precárias, com fins de exploração, não promova a aquisição de competências nem possibilite o estabelecimento de vínculos saudáveis ou facilite o desenvolvimento futuro. Mas generalizar esses prejuízos para qualquer tipo de trabalho não é correto, uma vez que, em vários contextos de inserção profissional, os jovens podem encontrar um ambiente de desenvolvimento de potencialidades, de integração social e de amadurecimento pessoal e profissional. Essas iniciativas positivas devem ser permanentemente identificadas e expandidas, para que a educação pelo trabalho seja uma alternativa real para a juventude brasileira assim como é em outras partes do mundo (Maia, 2008). Embora este trabalho permita pensar melhor sobre os diferentes aspectos envolvidos na primeira inserção laboral de jovens aprendizes e sobre como estes influenciam o seu desenvolvimento, é necessário que mais investigações sejam realizadas nesse sentido, especialmente buscando superar as limitações deste estudo no que diz respeito ao pequeno número de participantes e ao fato de que talvez apenas aqueles adolescentes mais satisfeitos com suas atividades tenham consentido em participar no estudo, o que cria um viés de percepção positiva da experiência de aprendizagem. Estudos de maior amplitude, com utilização de questionários anônimos, podem contribuir para corroborar os resultados aqui encontrados ou trazer novas perspectivas para a avaliação dos programas de aprendizagem. É importante também que novos estudos procurem identificar separadamente o papel do curso de treinamento, da empresa que acolhe o jovem aprendiz e também do supervisor, que apareceram aqui como proporcionadores de impactos relevantes e distintos na formação e na satisfação dos adolescentes. 
Heloiza de Sousa

Graduanda em Psicologia da Universidade Federal de Santa Catarina, Florianópolis - SC - Brasil.

E-mail: helloiza.sousa@gmail.com

\section{Denise Frozzi}

Graduada em Psicologia pela Universidade Federal de Santa Catarina, Florianópolis - SC - Brasil.

E-mail: denifrozzi@gmail.com

\section{Marucia Patta Bardagi}

Doutora em Psicologia pela Universidade Federal do Rio Grande do Sul e docente da Universidade Federal de Santa Catarina, Florianópolis - SC - Brasil.

E-mail: marucia.bardagi@gmail.com

Endereço para envio de correspondência:

Departamento de Psicologia, sala 14A, Campus Universitário UFSC Reitor João David Ferreira Lima. Trindade. CEP: 88040-970. Florianópolis, SC.

Recebido 17/08/2012, 1a Reformulação 19/01/2013, Aprovado 11/04/2013. 
Almeida, M. E. G. G., \& Pinho, L. V. (2008). Adolescência, família e escolhas: implicações na orientação profissional. Psicologia Clínica, 20(2), 173-184. doi: http://dx.doi.org/10.1590/ S0103-56652008000200013

Amazarray, M. R., Thomé, L. D., Souza, A. P. L., Poletto, M., \& Koller, S. H. (2009). Aprendiz versus trabalhador: adolescentes em processo de aprendizagem. Psicologia: Teoria e Pesquisa, 25(3), 329-338. doi: http://dx.doi.org/10.1590/S010237722009000300006

Bardin, L. (1977). Análise de conteúdo. Lisboa: Edições 70.
Brasil. (2000). Lei n. 10.097, de 19 de dezembro de 2000. Determina que todas as empresas de médio e grande porte contratem um número de aprendizes equivalentes a um mínimo de $5 \%$ e um máximo de $15 \%$ do seu quadro de funcionários cujas funções demandem formação profissional. Recuperado em 30 julho, 2012, de http://www.aprendizlegal. org.br/main.asp?Team $=\{44 \mathrm{BA} 8 \mathrm{D} 38-9 \mathrm{DCA}-4 \mathrm{C07}-9 \mathrm{F0B}-$ D0B0AD8710BA\}

Brasil. (2005). Decreto $n^{\circ}$ 5598/2005. Brasília, DF: Diário Oficial da União. 


\section{Referências}

Bressan, E. L., Godoy, A. M. A., \& Lunardelli, M. C. F. (2004). Saúde mental e trabalho: intervenções nas relações entre adolescentes trabalhadores e empresa. Revista Brasileira de Orientação Profissional, 5(2), 63-75.

Fischer, F. M., Oliveira, D. C., Teixeira, L. R., Teixeira, M. C. T. V., \& Amaral, M. A. (2003). Efeitos do trabalho sobre a saúde de adolescentes. Ciência \& Saúde Coletiva, 8(4), 973-984. doi: http://dx.doi.org/10.1590/S1413-81232003000400019

Gonçalves, C. M., \& Coimbra, J. L. (2002). Significados construídos em torno da experiência profissional/trabalho. Recuperado em 24 setembro, 2012, de www.psicologia. com.pt .

lamamoto, M. V. (2001). Trabalho e indivíduo social: um estudo sobre a condição operária na agroindústria canavieira paulista. São Paulo: Cortez.

Instituto Brasileiro de Geografia e Estatística - IBGE. (2010). Censo 2010. Recuperado em 23 de janeiro de 2012 de http:// www.ibge.gov.br/home/presidencia/noticias/noticia_visualiza. phpid_noticia $=2155 \&$ \&id_pagina $=1$

Jonhson, D. (1994). Focus groups. In D. Zweizig, D. W. Jonhson, J. Robbins, \& M. Besant (Eds.), Tell it! Evaluation sourcebook \& training manual. Madison: SLIS.

Krueger, R. A. (1988). Focus group: A pratical guide for applied research. Newbury Park: Sage Publications.

Lemos, C. G. (2000). O procedimento de desenhos-estórias de profissionais na pesquisa em orientação profissional. In Anais do V Encontro Mineiro de Avaliação Psicológica e VIII Conferência Internacional de Avaliação Psicológica - formas e contextos (pp.237-239). Belo Horizonte: Puc Minas.

Lima, S. M., \& Minayo-Gomez, C. (2003). Modos de subjetivação na condição de aprendiz: embates atuais. História, Ciências, Saúde-Manguinhos, 10(3), 931-953. doi: http://dx.doi. org/10.1590/S0104-59702003000300007

Maia, C. (2008). Work-based learning: a nova geração do e-learning? Diálogo Educação, 8(24), 459-472.

Mattos, E., \& Chaves, A. M. (2006). As representações do trabalho entre adolescentes aprendizes: um estudo piloto. Revista de Crescimento e Desenvolvimento Humano, 16, 66-75.

Mattos, E., \& Chaves, A. M. (2010). Trabalho e escola: é possível conciliar? A perspectiva de jovens aprendizes baianos. Psicologia: Ciência e Profissão, 30(3), 540-555. doi: http:// dx.doi.org/10.1590/S1414-98932010000300008

Morgan, D. L. (1988). Focus group as qualitative research (Qualitative Research Methods Series 16). Newbury Park: Sage Publication.

Oliveira, D. C., Sá, C. P., Fischer, F. M., Martins, I. S., \& Teixeira, L. R. (2001). Futuro e liberdade: o trabalho e a instituição escolar nas representações sociais de adolescentes. Estudos de Psicologia, 6(2), 245-258. doi: http://dx.doi.org/10.1590/ S1413-294X2001000200012

Oliveira, D. C., Fischer, F. M., Martins, I. S., \& Sá, C. P. (2003). Representações sociais e fatores de risco para o trabalho infantil e do adolescente: uma aproximação possível. Cadernos Saúde Coletiva, 10(2), 177-194.

Oliveira, D. C., Fischer, F. M., Teixeira, M. C. T. V., \& Amaral, M. A. (2003). A escola e o trabalho entre adolescentes do ensino médio da cidade de São Paulo: uma análise de representações sociais. Psicologia: Teoria e Prática, 5(1), 27-39.

Oliveira, D. C., Fischer, F. M., Teixeira, M. C. T. V., \& Gomes, A. M. T. (2005). Adolescência, trabalho e estudo: análise comparativa das representações sociais de adolescentes trabalhadores e não trabalhadores. Revista Enfermagem UERJ, 13(2), 229-237.

Oliveira, D. C., Fischer, F. M., Amaral, M. A., Teixeira, M. C. T. V., \& Sá, C. P. (2005). A positividade e a negatividade do trabalho nas representações sociais de adolescentes. Psicologia: Reflexão e Crítica, 18(1), 125-133. doi: http:// dx.doi.org/10.1590/S0102-79722005000100017

Oliveira, D. C., Gomes, A. M. T., Benite, A. M., \& Valois, B. R. G. (2006). Cotidiano e adolescência: representações e práticas de trabalho, escola, relacionamentos interpessoais e futuro. Revista Enfermagem UERJ, 4(2),182-190.

Oliveira, D. C., Fischer, F. M., Teixeira, M. C. T. V., Sá, C. P., \& Gomes, A. M. T. (2010). Representações sociais do trabalho: uma análise comparativa entre jovens trabalhadores e não trabalhadores. Ciência \& Sociedade Coletiva, 15(3), 763- 773.

Pochmann, M. (2005). Educação, trabalho e juventude: o dilema brasileiro e a experiência da prefeitura de São Paulo. In E. Abdala, C. Jacinto, A. Solla (Orgs.), La inclusión laboral de los jóvenes: entre la desesperanza y la contrucción coletiva. Montevidéo: CINTERFOR/OIT. Recuperado em 28 fevereiro, 2012 de prejal.oit.org.pe/prejal/docs/ bib/200711170032_4_2_0.pdf

Ramos, F. P., \& Menandro, P. R. M. (2010). Inserção laboral: mudanças na identidade e nas relações sociais de adolescentes de classe popular. Psico Porto Alegre, 33(2), 273-288.

Rizzo, C. B. S., \& Chamon, E. M. Q. (2011). O sentido do trabalho para o adolescente trabalhador. Trabalho, Educação e Saúde, 8(3), 407-417. doi: http://dx.doi.org/10.1590/S198177462010000300004

Rocha, N. M. F. D., \& Góis, C.W. L. (2010). Trajetórias de jovens no mundo do trabalho a partir da primeira inserção: o caso de Sísifo em Maracanaú - Ceará, Brasil. Psicologia \& Sociedade, 22(3), 466-475. doi: http://dx.doi.org/10.1590/ S0102-71822010000300007

Santos, L. M. M. (2005). O papel da família e dos pares na escolha profissional. Psicologia em Estudo, 10(1), 57-66. doi: http:// dx.doi.org/10.1590/S1413-73722005000100008

Saviani, D. (2007). Trabalho e educação: fundamentos ontológicos e históricos. Revista Brasileira de Educação, 12(34), 152-165. doi: http://dx.doi.org/10.1590/S141324782007000100012

Teixeira, M. A. O., Bardagi, M. P., \& Hutz, C. S. (2007). Escalas de exploração vocacional (EEV) para universitários. Psicologia em Estudo, 12(1), 175-182. doi: http://dx.doi.org/10.1590/ S1413-73722007000100023 